\title{
EVIDENCE THAT LECTIN-BINDING SITES ARE PRESENT ON THE SURFACE OF ISOLATED HYPOTHALAMIC GRANULES CONTAINING LUTEINIZING HORMONE-RELEASING HORMONE ${ }^{1}$
}

\author{
AYALLA BARNEA ${ }^{2}$ AND GLORIA CHO
}

Cecil H. and Ida Green Center for Reproductive Biology Sciences, The Departments of Obstetrics and Gynecology and Physiology, The University of Texas Health Science Cenler at Dallas, Southwestern Medical School, Dallas, Texas 75235

Received January 22, 1982; Revised April 23, 1982; Accepted May 25, 1982

\begin{abstract}
In the present study, we wished to ascertain if lectin-binding sites are present on hypothalamic granules containing luteinizing hormone-releasing hormone (LHRH). LHRH granules (isolated from homogenates of hypothalami of adult male rats by means of hypo-osmotic shock and differential centrifugation) were subjected to affinity chromatography on columns of concanavalin A (Con A)Sepharose. The amount of LHRH present in the unbound and bound fraction was measured by radioimmunoassay. Of the total LHRH present in the granule suspension chromatographed, 30 to $40 \%$ was bound to the columns, and this binding was not related to the binding of the bulk to the proteins. Synthetic LHRH by itself or synthetic LHRH added to the LHRH granules before chromatography did not bind to Con A-Sepharose, indicating that only LHRH contained within granules is retained on the columns. In addition, we found that the binding of LHRH granules to Con A-Sepharose has a requirement for $\mathrm{Ca}^{2+}$ and $\mathrm{Mn}^{2+}$ : after equilibration of Con A-Sepharose with $\mathrm{Ca}^{2+}$ and $\mathrm{Mn}^{2+}$ (prior to the chromatography), all of the LHRH granules were bound to the columns, and this binding was prevented by EDTA. To examine the specificity of the binding of LHRH granules to Con A-Sepharose, a competing sugar ( $\alpha$-methyl-D-mannoside $(\alpha-\mathrm{MM})$ ) was added to the LHRH granules, and the columns were equilibrated with $\alpha$-MM prior to chromatography. Under this condition, the $\mathrm{Ca}^{2+}$ - and $\mathrm{Mn}^{2+}$-dependent binding of LHRH granules to Con A-Sepharose was inhibited. In addition to Con A-Sepharose, we observed that LHRH granules bind to wheat germ agglutinin-Sepharose but not to Sepharose which does not contain a lectin. These findings are indicative that lectin-binding sites, carbohydrate in nature, are present on the surface of isolated LHRH granules. We propose that such binding sites may play a role in the release of LHRH from hypothalamic neurons.
\end{abstract}

Luteinizing hormone-releasing hormone (LHRH), which is stored in granule-like particles within hypothalamic neurons (Pelletier et al., 1974; Goldsmith and Ganong, 1975; Barnea et al., 1976, 1978a, b; Styne et al., 1977), is released into the hypophysial portal vessels under physiological conditions (Eskay et al., 1975, 1977). Since it has been shown that many polypeptides are released from secretory cells by exocytosis (Douglas, 1974; Palade, 1975; Putney et al., 1978), it is conceivable that the release of LHRH also occurs by exocytosis. An important

\footnotetext{
${ }^{1}$ We wish to thank Jodie Roberts, Gaye Burnsed, and Robert Lipsey for their excellent technical assistance and Margaret Carlisle for editorial assistance. This work was supported by Research Grants AM25692 and AG00306 from the National Institutes of Health, Bethesda, MD.

${ }^{2}$ To whom correspondence should be addressed at Department of Obstetrics and Gynecology, The University of Texas Health Science Center at Dallas, 5323 Harry Hines Boulevard, Dallas, TX 75235.
}

event in the process of exocytosis is the fusion of the membrane of the secretory granule with the plasma membrane of the cell. In order for such a specific membrane-membrane interaction to occur, specific recognition sites should be present on the surface of the secretory granule and the plasma membrane.

The terminal carbohydrate moieties of glycoproteins and glycolipids have been implicated in membrane-membrane interactions and particularly in the process of recognition (cf., Sharon and Lis, 1972; Shur and Roth, 1975; Margolis and Margolis, 1977). Hence, it can be envisioned that carbohydrate moieties of membrane glycoconjugates, exposed on the surface of LHRH granules, may play an important role in the interaction between the granules and the plasma membrane and, hence, in the release of LHRH.

The binding of lectins (carbohydrate-binding proteins) to membranes has been employed, by many investigators, 
as a tool in the study of membrane carbohydrates. Therefore, in the present study, we addressed the question: are lectin-binding sites present on the surface of isolated hypothalamic LHRH granules? LHRH granules were isolated from rat hypothalami and then subjected to affinity chromatography on columns of concanavalin A (Con-A)-Sepharose or wheat germ agglutinin (WGA)Sepharose. The finding that LHRH granules bind to these immobilized lectins is suggestive that tightly bound carbohydrates are present on the surface of the LHRH granules.

\section{Materials and Methods}

Animals. Adult male rats (200 to $250 \mathrm{gm}$ ) of the LongEvans strain were used. The animals were decapitated, and their brains were removed rapidly and chilled in ice cold $0.15 \mathrm{~m} \mathrm{NaCl}$. The hypothalamus was excised as described earlier (Barnea et al., 1977).

Preparation of $L H R H$ granules. All operations were carried out at $4^{\circ} \mathrm{C}$, and all sucrose or lactose solutions contained $10 \mu \mathrm{M} \mathrm{CaCl} 2$ and $0.05 \%$ bacitracin. Four hypothalami were homogenized in $1.0 \mathrm{ml}$ of $0.32 \mathrm{M}$ sucrose with a Duall tissue grinder and Teflon pestle (K-885480, Kontes Glass Co., Vineland, NJ) using 10 up-and-down strokes. The homogenate was diluted to a final concentration of $0.16 \mathrm{M}$ sucrose and then centrifuged for $10 \mathrm{~min}$ at $900 \times \mathrm{g}$. The $900 \times \mathrm{g}$ supernatant fluid was centrifuged for $8 \mathrm{~min}$ at $10,000 \times \mathrm{g}$, the pellet was washed once with $1.0 \mathrm{ml}$ of $0.16 \mathrm{~m}$ sucrose, and the $10,000 \times \mathrm{g}$ supernatant fluids were combined and then centrifuged for $15 \mathrm{~min}$ at $40,000 \times g$. (We have shown previously that a $40,000 \times$ $g$ pellet prepared in such a manner contains LHRH granules free of synaptosomes (Barnea et al., 1978a).) The $40,000 \times g$ pellet was resuspended in $0.8 \mathrm{ml}$ of 0.32 $\mathrm{M}$ lactose, and then $0.8 \mathrm{ml}$ of a solution of $0.02 \mathrm{M}$ phosphate buffer ( $\mathrm{pH} 7.5$ ) containing $0.2 \mathrm{M} \mathrm{NaCl}$ was added (the reason for suspending the LHRH granules in 0.32 $\mathrm{M}$ lactose rather than in $0.32 \mathrm{M}$ sucrose is that sucrose is known to bind to Con A, whereas lactose does not (Goldstein et al., 1965; Agrawal and Goldstein, 1967)). This suspension, which was used for the affinity chromatography studies, will be referred to as "granule suspension." Of the total LHRH present in the homogenate, $60 \pm 2.0 \%$ (mean $\pm \mathrm{SEM} ; N=17$ ) was recovered in the granule suspension.

Affinity chromatography of LHRH granules. Con ASepharose (10 mg of Con A/ml of packed gel), WGASepharose (5 mg of WGA/ml of packed gel), and Sepharose $4 \mathrm{~B}$ were purchased from Sigma Chemical Co., St. Louis, MO. The Con A-Sepharose contains $\mathrm{Ca}^{2+}$ and $\mathrm{Mn}^{2+}$, and therefore, these ions were not included in the chromatography buffer. On the day before the experiment, an aliquot of the suspension of the immobilized lectin was washed with $60 \mathrm{vol}$ of $0.01 \mathrm{M}$ phosphate buffer (pH 7.5). On the day of the experiment, the immobilized lectin was washed with $16 \mathrm{vol}$ of lactose/phosphate buffer $(0.01 \mathrm{M}$ phosphate buffer, $\mathrm{pH} 7.5$, containing $0.1 \mathrm{M} \mathrm{NaCl}$, $0.16 \mathrm{~m}$ lactose, $10 \mu \mathrm{M} \mathrm{CaCl}$, and $0.05 \%$ bacitracin). The washed lectin-Sepharose was suspended in 2 vol of lactose/phosphate buffer, and columns of 0.75 or $1.5 \mathrm{ml}$ of packed gel were prepared in polypropylene Econo-Columns (Bio-Rad Laboratories, Inc., Richmond, CA). To

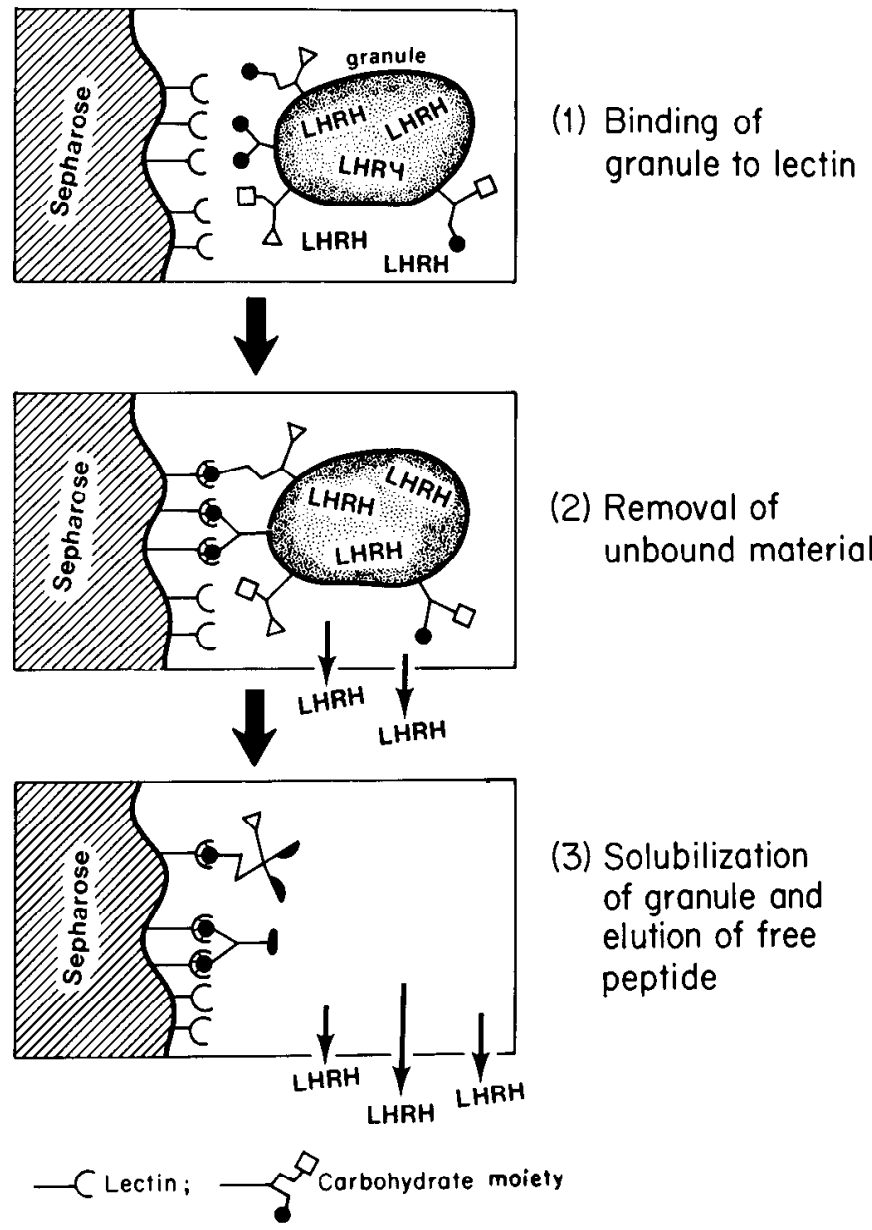

Figure 1. Schematic representation of the procedure of affinity chromatography of LHRH granules on immobilized lectins.

ascertain whether lactose would interfere with the binding of carbohydrate moieties to the immobilized lectins, we subjected ${ }^{125}$ I-follicle-stimulating hormone (a glycoprotein) to affinity chromatography and found that lactose did not interfere with the binding to either Con ASepharose or WGA-Sepharose. Immobilized lectins were used once and then discarded.

The binding of LHRH granules to Con A-Sepharose, WGA-Sepharose, or Sepharose $4 \mathrm{~B}$ was carried out in the following manner (Fig. 1). An aliquot (0.3 or $0.6 \mathrm{ml}$ ) of the granule suspension was layered on the column. After the granules had entered the gel, $60 \mu \mathrm{l}$ of lactose/phosphate buffer was layered on top of the granules. This procedure took about $1 \mathrm{~min}$. Granules were exposed to the columns for a designated time, after which the columns were washed three times with $1.0 \mathrm{ml}$ of lactose/ phosphate buffer (unbound fractions) and then four times with $1.0 \mathrm{ml}$ of $0.1 \%$ Triton X-100 prepared in lactose/phosphate buffer (bound fractions). Column fractions and aliquots of the granule suspension were heated in a boiling water bath for $10 \mathrm{~min}$ and then frozen at $-20^{\circ} \mathrm{C}$ to await assays (Barnea et al., 1977). The recovery of LHRH from the columns was $96 \pm 2 \%(N=21)$; the recovery of protein was $64 \pm 3.3 \%(N=8)$.

Assay of $L H R H$. LHRH was quantified by radioimmunoassay according to the method of Nett et al. (1973), 
using synthetic LHRH (Beckman Instruments, Inc., Palo Alto, CA) as the reference standard. Bacitracin and Triton X-100 were added to each assay tube to a final concentration of $0.01 \%$ and $0.02 \%$, respectively. We have shown previously that these concentrations of bacitracin and Triton X-100 do not interfere with the assay (Barnea et al., 1976, 1978b).

Assay of protein. Perchloric acid was added to an aliquot of each column fraction or granule suspension to a final concentration of $0.3 \mathrm{M}$. Samples were kept at $4^{\circ} \mathrm{C}$ for $20 \mathrm{~min}$; proteins were pelleted and washed once with $0.3 \mathrm{M}$ perchloric acid. Proteins were dissolved in $0.5 \mathrm{M}$ $\mathrm{NaOH}$ and quantified according to the method of Lowry et al. (1951), using bovine serum albumin as the reference standard.

Each experiment was carried out in duplicate or triplicate, and each experimental protocol was repeated three to six times.

\section{Results}

Binding of LHRH granules to immobilized lectins. When a granule suspension was chromatographed on Con A-Sepharose (columns of $0.75 \mathrm{ml}$; exposure of granules to columns for $15 \mathrm{~min}$ ), about $80 \%$ of the total LHRH fractionated was recovered in the unbound fraction and $20 \%$ was bound to the columns. First, we attempted to recover the LHRH granules that were bound to the columns by displacing them with a competing sugar (1.0 M $\alpha$-methyl-D-mannoside ( $\alpha-\mathrm{MM})$ ). However, we found that $\alpha$-MM did not displace the bound LHRH granules from Con A-Sepharose (Fig. 2). Therefore, we attempted to recover the LHRH that was retained on the columns by disrupting the granules. Since we have observed previously that Triton $\mathrm{X}-100$ solubilizes the $\mathrm{LHRH}$ granules (Barnea et al., 1976), we washed the columns with a solution of $0.1 \%$ Triton X-100 and found that all of the LHRH that was retained on the columns was eluted. This finding suggests that granules containing LHRH bind to Con A-Sepharose. However, it is possible that the granule suspension also contains free LHRH that was adsorbed to particulate matter which binds to Con A-Sepharose. To test this possibility, synthetic LHRH, a granule suspension, or synthetic LHRH mixed with a granule suspension was subjected to affinity chromatography. As shown in Table I, the amount of LHRH retained on the column after chromatography of a granule suspension alone or of a mixture of a granule suspension and synthetic LHRH was similar; LHRH by itself was not retained on the column. Based on these findings (Fig. 2; Table I), we concluded that (1) free LHRH or LHRH adsorbed to particulate matter in the suspension does not bind to Con A-Sepharose, (2) LHRH granules bind to Con A-Sepharose, and (3) the binding of LHRH granules to the immobilized lectin can be quantified by measuring the amount of LHRH retained on the column and solubilized by Triton X-100.

The binding of LHRH granules to Con A-Sepharose may be due to binding of the granules to the lectin and/ or to the Sepharose. To distinguish between these two possibilities, granule suspensions (containing $0.125,0.25$, or 0.5 hypothalamic equivalents) were subjected to chromatography on Con A-Sepharose, WGA-Sepharose, or

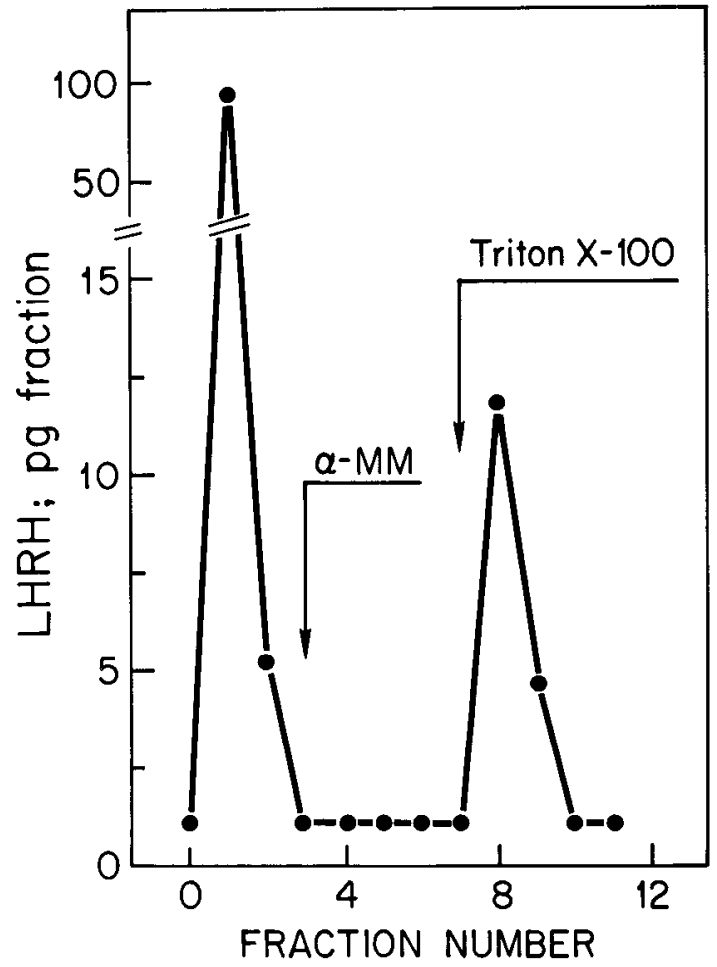

Figure 2. Affinity chromatography of LHRH granules on columns of Con A-Sepharose. A granule suspension containing 0.5 hypothalamic equivalents was subjected to affinity chromatography on columns $(0.75 \mathrm{ml})$ of Con A-Sepharose. After exposure of the granules to the Con A-Sepharose $(15 \mathrm{~min})$, the columns were washed three times with $1 \mathrm{ml}$ of lactose/phosphate buffer, four times with $1 \mathrm{ml}$ of $1 \mathrm{M} \alpha$-methyl-D-mannoside $(\alpha$-MM) prepared in phosphate buffer ( $\mathrm{pH} 7.5)$ containing 10 $\mu \mathrm{M} \mathrm{CaCl}_{2}$ and $0.05 \%$ bacitracin, and then four times with $1 \mathrm{ml}$ of $0.1 \%$ Triton X-100 prepared in lactose/phosphate buffer.

TABLE I

Binding of LHRH granules to Con A-Sepharose

Synthetic LHRH, a granule suspension (containing 0.2 hypothalamic equivalents), or a mixture of synthetic LHRH and a granule suspension was subjected to affinity chromatography for $15 \mathrm{~min}$ on columns $\mathbf{( 0 . 7 5}$ ml) of Con A-Sepharose as described under "Materials and Methods." Each value is the mean of triplicate determinations.

\begin{tabular}{lcc}
\hline \multicolumn{1}{c}{ Sample Chromatographed } & LHRH Bound & LHRH Unbound \\
\hline & \multicolumn{2}{c}{$p g$} \\
Experiment 1 & $\mathrm{U.D.}^{\alpha}$ & 982 \\
$\quad$ Synthetic LHRH & 202 & 534 \\
Granule suspension & 226 & 1456 \\
Synthetic LHRH + & & \\
$\quad$ granule suspension & & \\
& & \\
Experiment 2 & U.D. ${ }^{a}$ & 920 \\
Synthetic LHRH & 103 & 358 \\
Granule suspension & 109 & 1214 \\
Synthetic LHRH + & & \\
$\quad$ granule suspension & & \\
\hline${ }^{a}$ U.D., undetectable. & &
\end{tabular}

Sepharose 4B. As shown in Figure 3, LHRH granules were found to bind to Con A-Sepharose and WGA-Sepharose but not to Sepharose $4 B$ which did not contain a lectin. This result is indicative that the binding of LHRH granules to columns of immobilized lectins is due to an 


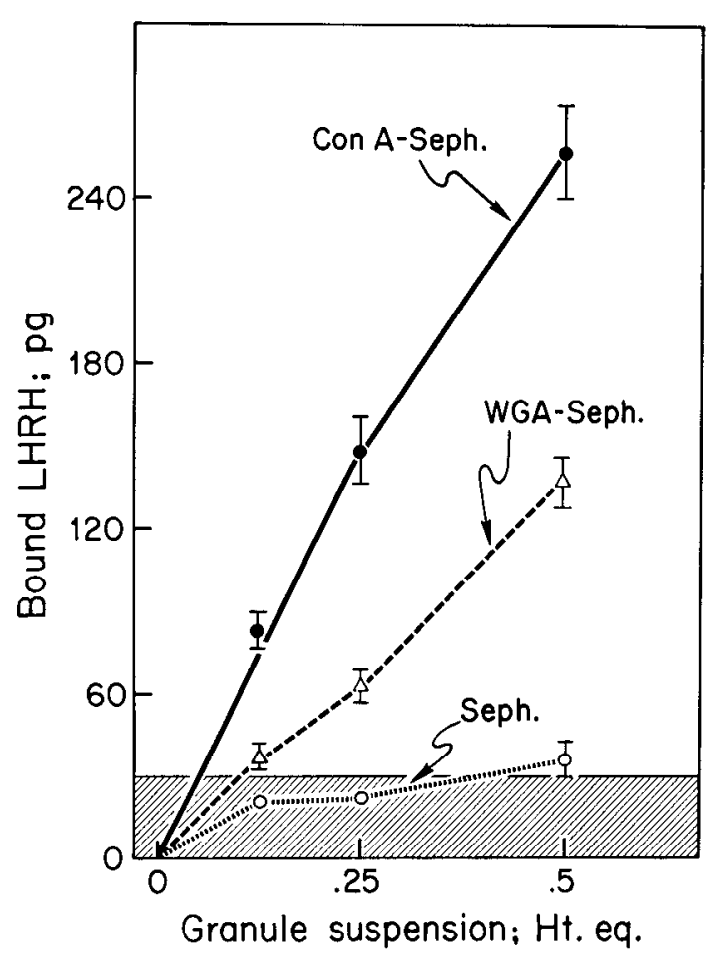

Figure 3. Lectin specificity of the binding of LHRH granules. A granule suspension containing $0.125,0.25$, or 0.5 hypothalamic equivalents (Ht. eq.) in $0.3 \mathrm{ml}$ of lactose/phosphate buffer was subjected to affinity chromatography for $15 \mathrm{~min}$ on columns $(0.75 \mathrm{ml})$ of Con A-Sepharose, WGA-Sepharose, or Sepharose 4B as described under "Materials and Methods." Each point is the mean \pm SEM of six to nine values obtained from three different experiments. The shaded area represents the amount of LHRH that is below the level of detectability of the assay.

interaction of the granules with the lectin and not with the Sepharose. It is interesting that, regardless of the concentration of the LHRH granules in the granule suspension, the binding of LHRH granules to Con A-Sepharose was twice that of the binding to WGA-Sepharose and that the amount of protein bound to Con A-Sepharose and then eluted with $0.1 \%$ Triton $\mathrm{X}-100$ was also twice that bound to WGA-Sepharose. It should be noted that a substantial amount of the protein that was bound to Con A-Sepharose or WGA-Sepharose was not eluted with $0.1 \%$ Triton X-100 (nonrecoverable proteins). Since it is known that Triton X-100 does not interfere with the binding of carbohydrate moieties to Con A or WGA, it is reasonable to assume that the nonrecoverable proteins are glycoproteins. We found that the amount of these glycoproteins bound to Con A-Sepharose was also twice that bound to WGA-Sepharose (the amount of glycoprotein bound to the columns was computed by subtracting the amount of protein recovered in the unbound and bound fractions from the total chromatographed).

Since the binding of LHRH granules to Con A-Sepharose was greater than that to WGA-Sepharose, in the following experiments, we further characterized the binding of the granules to the lectins using Con A-Sepharose columns.

As mentioned above, only $20 \%$ of the total LHRH present in the granule suspension was retained on Con
A-Sepharose. Therefore, we wished to ascertain if the LHRH granules, present in the unbound fraction, are capable of binding to Con A-Sepharose. A granule suspension containing 0.5 hypothalamic equivalents was chromatographed on a column of Con A-Sepharose (first chromatography). An aliquot of the first unbound fraction was rechromatographed on another column of Con A-Sepharose (second chromatography). The amount of LHRH retained on the columns in the first chromatography was $330 \pm 29 \mathrm{pg}$ (mean $\pm \mathrm{SEM} ; N=14$ ), and in the second chromatography, it was $290 \pm 29 \mathrm{pg}$, indicating that the unbound fraction contains LHRH granules which are capable of binding to Con A-Sepharose. Of the total LHRH present in the granule suspension, $39 \pm 2.5 \%$ was retained on the columns after the first and second chromatography. In this experiment, we also determined the ratio (picograms per micrograms) of bound LHRH to total bound protein (total bound protein equals the total amount of protein chromatographed minus the amount of protein recovered in unbound fraction). The reason for conducting this measurement is that $\mathrm{LHRH}$ granules account for a small fraction of the total protein in the granule suspension. Therefore, two possibilities should be considered: (1) LHRH granules by themselves bind to Con $A$, and, in this case, the ratio of bound LHRH to bound protein in the second chromatography should be higher than that in the first; (2) LHRH granules by themselves do not bind to Con A, and the apparent binding of LHRH granules is due to LHRH granules entrapped in and/or adsorbed to other particles which bind to Con $A$. In this case, the ratio of bound LHRH to bound protein should be similar in the two chromatographies. We found that the ratio of bound LHRH to bound protein was $1.5 \pm 0.11(N=7)$ in the first chromatography and $10.0 \pm 0.98$ in the second, indicating that LHRH granules by themselves bind to Con A-Sepharose.

In the studies described above, we used columns consisting of $0.75 \mathrm{ml}$ of packed gel, and the granules were exposed to the columns for $15 \mathrm{~min}$; under these conditions, only $20 \%$ of the total $\mathrm{LHRH}$ was retained on the columns. However, it is possible that greater binding of LHRH to Con A-Sepharose could be achieved by increasing the size of the columns and the time of exposure of the granules to the columns. In the following experiment, we used columns consisting of $1.5 \mathrm{ml}$ of packed gel, and the granules were exposed to the columns for 20,30 , or $45 \mathrm{~min}$. Of the total LHRH chromatographed, $30 \%$ was retained on columns consisting of $1.5 \mathrm{ml}$ of packed gel as compared to $20 \%$ retained on columns consisting of 0.75 $\mathrm{ml}$ of packed gel. Nevertheless, the retention of $\mathrm{LHRH}$ was not affected by increasing the exposure time of the granules on the columns from 20 to $45 \mathrm{~min}$.

Characterization of the binding of LHRH granules to Con A-Sepharose. Con A is a protein which binds specifically to molecules containing terminal nonreducing $\alpha$ D-mannopyranosyl or sterically related residues; this binding has a requirement for $\mathrm{Ca}^{2+}$ and $\mathrm{Mn}^{21}$ (Goldstein et al., 1965; Smith and Goldstein, 1967; So and Goldstein, 1968; Lis and Sharon, 1973). In spite of its high specificity, Con A also binds to polyelectrolytes and polysaccharides which are devoid of terminal mannopyranosyl (or related) residues. However, it is possible to distinguish 
between the specific and nonspecific binding reactions of Con $\mathrm{A}$ in the following manner: the specific binding to Con A is inhibited by saccharides, whereas the nonspecific binding is not (Sharon and Lis, 1972). From the data presented in Figure 2, it is evident that once the LHRH granules became attached to the Con A-Sepharose, $\alpha$ MM failed to displace the granules from the columns. Therefore, we attempted to inhibit the binding of the LHRH granules to Con A-Sepharose by adding the $\alpha$ MM $(0.16 \mathrm{M})$ to the granule suspension before the affinity chromatography and found that binding was not inhibited (Fig. 4). On the other hand, when $\alpha$-MM $(0.16$ M) was added to the granule suspension and the columns were equilibrated with $\alpha$-MM before chromatography, the binding of LHRH granules was inhibited by at least $50 \%$ (Figs. 4 and 5 ).

The requirement for $\mathrm{Ca}^{2+}$ and $\mathrm{Mn}^{2+}$ for the binding of LHRH granules to Con A-Sepharose was addressed in the following manner. Five batches of Con A-Sepharose were equilibrated overnight in one of the following solutions: $(A)$ lactose/phosphate buffer; $(B)$ lactose/phosphate buffer containing $10 \mathrm{~mm}$ EDTA; $(C)$ lactose/phosphate buffer containing $0.1 \mathrm{mM} \mathrm{CaCl} 2$ and $0.1 \mathrm{~mm} \mathrm{MnCl}_{2}$; $(D)$ lactose/phosphate buffer containing $0.1 \mathrm{~mm} \mathrm{CaCl}_{2}$, $0.1 \mathrm{mM} \mathrm{MnCl}_{2}$, and $10 \mathrm{~mm}$ EDTA; or $(E)$ phosphate

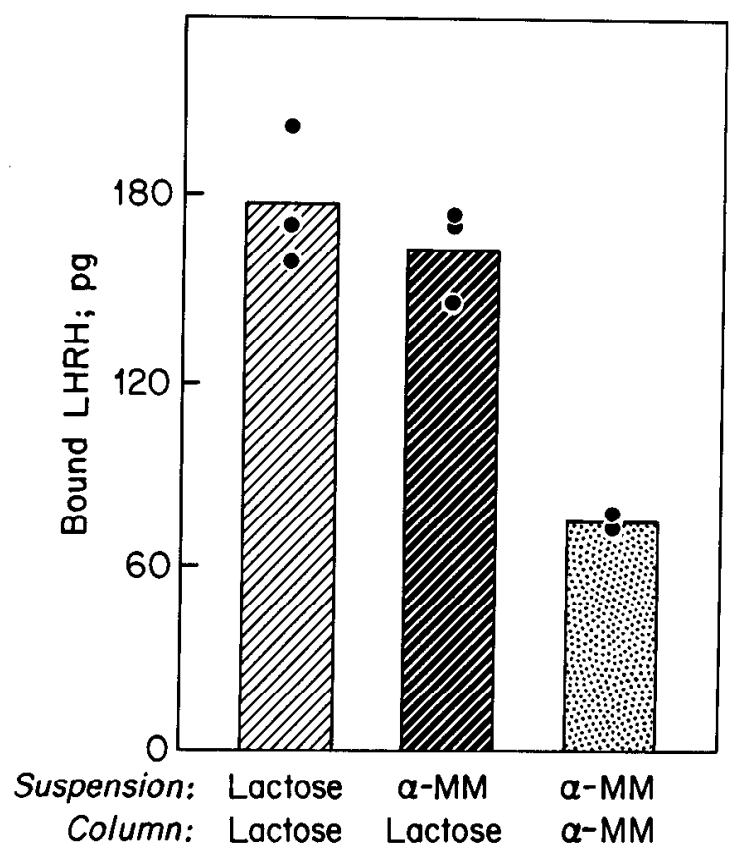

Figure 4. Conditions for the inhibition of the binding of LHRH granules to Con A-Sepharose by $\alpha$-methyl-D-mannoside $(\alpha-M M)$. A granule suspension containing 0.2 hypothalamic equivalents was chromatographed under one of the following conditions: (1) the granule suspension and the chromatography buffer contained $0.16 \mathrm{M}$ lactose (left bar), (2) the granule suspension contained $0.16 \mathrm{M} \alpha-\mathrm{MM}$ and the chromatography buffer contained $0.16 \mathrm{M}$ lactose (middle bar), and (3) the granule suspension contained $0.16 \mathrm{M} \alpha$-MM and the columns were equilibrated with $\alpha$-MM before chromatography (right bar). Columns of $0.75 \mathrm{ml}$ were used, and granules were exposed to the columns for $15 \mathrm{~min}$. The data presented were obtained within the same experiment and each point is a single determination.

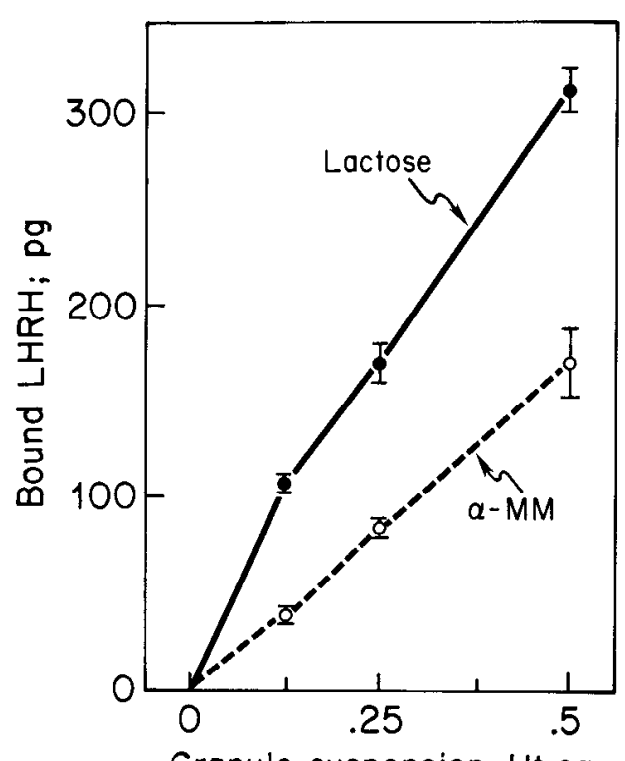

Granule suspension; Ht.eq.

Figure 5. Inhibition of the binding of LHRH granules to Con A-Scpharose by $\alpha$-methyl-D-mannoside $(\alpha-M M)$ as a function of the amount of the granule suspension chromatographed. Two sets of granule suspensions each containing $0.125,0.25$, or 0.5 hypothalamic equivalents ( $H t$. eq.) in $0.3 \mathrm{ml}$ of lactose/ phosphate buffer were chromatographed on columns of Con ASepharose. For the chromatography of one set of granules (-), the granule suspension and the chromatography buffer contained $0.16 \mathrm{~m}$ lactose (for details, see "Materials and Methods"). For the chromatography of the other set of granules $(\mathrm{O}---\bigcirc), \alpha-\mathrm{MM}$ was added to the granule suspension to a final concentration of $0.16 \mathrm{M}$, and the lactose in the equilibration and chromatography buffer (lactose/phosphate) was replaced by $0.16 \mathrm{M} \alpha$-MM. Columns of $0.75 \mathrm{ml}$ were used, and granules were exposed to the columns for $15 \mathrm{~min}$. Each point is the mean of six values obtained in two different experiments.

buffer containing $0.16 \mathrm{M} \alpha-\mathrm{MM}, 0.1 \mathrm{mM} \mathrm{CaCl}$, and 0.1 $\mathrm{mM} \mathrm{MnCl} 2$. Columns $(1.5 \mathrm{ml})$ were washed with $2 \mathrm{ml}$ of lactose/phosphate buffer ( $A$ to $D$ ) or phosphate buffer containing $0.16 \mathrm{M} \alpha-\mathrm{MM}(E)$, and then LHRH granules were subjected to affinity chromatography for $30 \mathrm{~min}$. We found that the binding of LHRH granules to Con ASepharose equilibrated with $\mathrm{Ca}^{2+}$ and $\mathrm{Mn}^{2+}$ (Fig. $6 \mathrm{C}$ ) was three times greater than the binding to Con ASepharose equilibrated with lactose/phosphate buffer alone (Fig. $6 A$ ). In both cases, the binding was inhibited dramatically by EDTA (Fig. $6, B$ and $D$ ). Furthermore, the $\mathrm{Ca}^{2+}$ - and $\mathrm{Mn}^{2+}$-dependent binding of LHRH granules to Con A-Sepharose was inhibited by $\alpha$-MM $(50 \%$ inhibition; Fig. $6 E$ ). It should be emphasized that essentially all of the LHRH granules chromatographed on Con A-Sepharose equilibrated with $\mathrm{Ca}^{2+}$ and $\mathrm{Mn}^{2+}$ were retained on the columns. These findings suggest that binding of LHRH granules to Con A-Sepharose involves an interaction between terminal residues which are related sterically to $\alpha$-D-mannopyranosyl and Con A.

\section{Discussion}

In the present study, we demonstrate that LHRH granules, isolated from hypothalamic tissue, bind to Con A-Sepharose and WGA-Sepharose. Five lines of evidence support our proposal that this binding is a result of a 


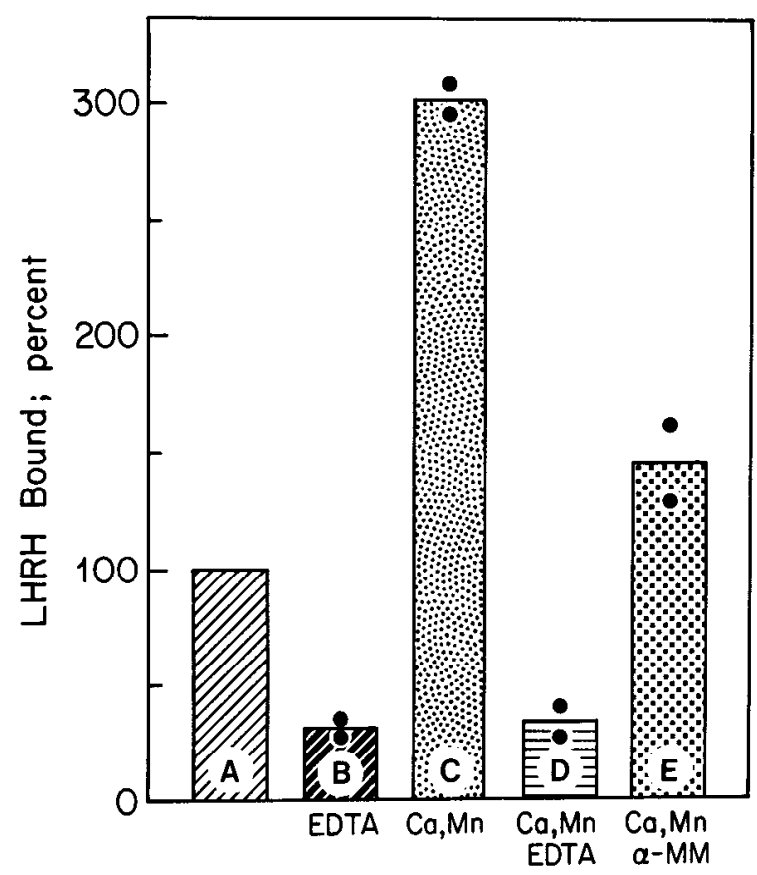

Treatment of Con A-Sepharose

Figure 6. Requirement for $\mathrm{Ca}^{2+}$ and $\mathrm{Mn}^{2+}$ for the binding of LHRH granules to Con A-Sepharose. Con A-Sepharose was equilibrated overnight in one of the following solutions: $(A)$ lactose/phosphate buffer; $(B)$ lactose/phosphate buffer containing $10 \mathrm{~mm}$ EDTA; $(C)$ lactose/phosphate buffer containing $0.1 \mathrm{mM} \mathrm{CaCl}{ }_{2}$ and $0.1 \mathrm{mM} \mathrm{MnCl}_{2} ;(D)$ lactose/phosphate buffer containing $0.1 \mathrm{mM} \mathrm{CaCl}, 0.1 \mathrm{~mm} \mathrm{MnCl}$, and $10 \mathrm{~mm}$ EDTA; or (E) phosphate buffer containing $0.16 \mathrm{mM} \alpha-\mathrm{MM}, 0.1 \mathrm{mM} \mathrm{CaCl}_{2}$, and $0.1 \mathrm{mM} \mathrm{MnCl}$. Columns $(1.5 \mathrm{ml})$ were washed with $2 \mathrm{ml}$ of lactose/phosphate buffer ( $A$ to $D$ ) or phosphate buffer containing $0.16 \mathrm{~mm} \alpha$-MM $(E)$, and then LHRH granules (0.35 hypothalamic equivalents) were subjected to affinity chromatography for $30 \mathrm{~min}$ as described under "Materials and Methods." Each point is the mean of three determinations. Binding to Con A-Sepharose equilibrated with lactose/phosphate buffer alone (A) was taken as $100 \%$.

specific interaction between the LHRH granule and the lectin. (1) Synthetic LHRH, added to the granules before chromatography, does not bind to Con A-Sepharose (Table I). (2) LHRH granules do not bind to Sepharose (Fig. 3). (3) The binding of LHRH granules to Con ASepharose is not a consequence of the binding of the bulk of the proteins in the granule suspension. (4) The binding of LHRH granules to Con A-Sepharose requires $\mathrm{Ca}^{2+}$ and $\mathrm{Mn}^{2+}$ and is prevented by EDTA (Fig. 6). (5) The binding of LHRH granules to Con A-Sepharose is inhibited by the competing sugar, $\alpha$-MM (Figs. 4 to 6 ). So and Goldstein (1968) have shown that di- or trisaccharides of mannose are stronger inhibitors of the binding of dextran to Con A than is $\alpha$-MM. They proposed that the binding site of Con A may be directed toward several saccharide residues. Walsh et al. (1976) have shown that isolated plasma membranes bind to Con A-Sepharose and that $\alpha$-MM does not displace the bound membranes from the lectin. They suggested that this tight binding of the membranes to Con $\mathrm{A}$ is a result of multivalent interactions. We noted that, in order for $\alpha$-MM to inhibit the binding of LHRH granules to Con A-Sepharose, the sugar had to be present in a high concentration during the binding reaction (Fig. 4). Furthermore, once LHRH granules became attached to Con A-Sepharose, $\alpha$-MM did not displace the granules from the lectin (Fig. 2). These findings are consistent with the interpretation that multivalent interactions may be involved in the binding of LHRH granules to Con A-Sepharose.

Our finding that LHRH granules bind to Con A-Sepharose and WGA-Sepharose indicates that the carbohydrate moieties involved in this interaction are present on the surface of the granule. However, at the present time, one could only speculate on the nature of the association between these surface carbohydrates and the granules. Glycoconjugates (glycolipids and glycoproteins) are integral components of membranes (Chapman, 1975; Marchesi, 1975; Singer, 1975), and it is well established that glycoconjugates are formed within the rough endoplasmic reticulum and the Golgi complex (Leblond and Bennett, 1977). One possibility is that the carbohydrate moieties of a membrane glycoconjugate(s), exposed on the surface of the granules, are involved in the interaction between the lectin and the granules. If so, an intriguing question arises: how do the carbohydrate moieties become oriented toward the cytoplasmic surface of the granule? Another possibility is that these carbohydrates are not intrinsic components of the granule membrane but that they are part of a glycoconjugate that is bound to the surface of the granule. Such a binding could exist in the intact cell and/or could occur during the process of isolation of the granules. Further investigation will clarify this important issue.

Membranes of chromaffin granules isolated from the adrenal medulla contain several glycoproteins (Cahill and Morris, 1979; Huber et al., 1979). Meyer and Burger (1976) have shown that carbohydrate moieites are exposed on the surface of isolated chromaffin granules. It is interesting that, in contrast to the LHRH granules, the carbohydrate moieties of chromaffin granules interact with WGA but not with Con A. Thus, it would appear that specific carbohydrate moieties are exposed on the surface of secretory granules. We propose that such carbohydrate moieties may play an important role in a specific membranc-mombrane interaction, such as exocytosis, and hence, in the release of LHRH.

\section{References}

Agrawal, B. B. L., and I. J. Goldstein (1967) Protein-carbohydrate interaction. VI. Isolation of concanavalin A by specific adsorption on cross-linked dextran gels. Biochim. Biophys. Acta 147: 262-271.

Barnea, A., N. Ben-Jonathan, and J. C. Porter (1976) Characterization of hypothalamic subcellular particles containing luteinizing hormone releasing hormone and thyrotropin releasing hormone. J. Neurochem. 27: 477-484.

Barnea, A., C. Oliver, and J. C. Porter (1977) Subcellular localization of $\alpha$-melanocyte-stimulating hormone in the rat hypothalamus. J. Neurochem. 29: 619-624.

Barnea, A., W. B. Neaves, G. Cho, and J. C. Porter (1978a) A subcellular pool of hypo-osmotically resistant particles containing thyrotropin releasing hormone, $\alpha$-melanocyte stimulating hormone, and luteinizing hormone releasing hormone in the rat hypothalamus. J. Neurochem. 30: 937-948.

Barnea, A., W. B. Neaves, G. Cho, and J. C. Porter (1978b) 
Demonstration of a temperature-dependent association of thyrotropin releasing hormone, $\alpha$-melanocyte stimulating hormone, and luteinizing hormone releasing hormone with subneuronal particles in hypothalamic synaptosomes. J. Neurochem. 31: 1125-1134.

Cahill, A. L., and S. J. Morris (1979) Soluble and membrane lectin-binding glycoproteins of the chromaffin granule. J. Neurochem. 32: 855-867.

Chapman, D. (1975) Lipid dynamics in cell membranes. In Cell Membranes: Biochemistry, Cell Biology, and Pathology, G. Weissmann and R. Claiborne, eds., pp. 13-22, HP Publishing Co., New York.

Douglas, W. W. (1974) Mechanism of release of neurohypophysial hormones: Stimulus-secretion couplings. In Handbook of Physiology. Vol. IV: Endocrinology, E. Knobil and W. H. Sawyer, eds., Sect. 7, pp. 191-224, American Physiological Society, Bethesda, MD.

Eskay, R. L., J. Warberg, R. S. Mical, and J. C. Porter (1975) Prostaglandin $\mathrm{E}_{2}$-induced release of LHRH into hypophysial portal blood. Endocrinology 97: 816-824.

Eskay, R., R. S. Mical, and J. C. Porter (1977) Relationship between luteinizing hormone releasing hormone concentration in hypophysial portal blood and luteinizing hormone release in intact, castrated, and electrochemically-stimulated rats. Endocrinology 100: 263-270.

Goldsmith, P. C., and W. F. Ganong (1975) Ultrastructural localization of luteinizing hormone-releasing hormone in the median eminence of the rat. Brain Res. 97: 181-193.

Goldstein, I. J., C. E. Hollerman, and E. E. Smith (1965) Protein-carbohydrate interaction. II. Inhibition studies on the interaction of concanavalin A with polysaccharides. Biochemistry 4: 876-883.

Huber, E., P. König, G. Schuler, W. Aberer, H. Plattner, and H. Winkler (1979) Characterization and topography of the glycoproteins of adrenal chromaffin granules. J. Neurochem. 32 35-47.

Leblond, C. P., and G. Bennett (1977) Role of the Golgi apparatus in terminal glycosylation. In International Cell Biol. ogy, B. R. Brinkley and K. R. Porter, eds., pp. 326-336, Rockefeller University Press, New York.

Lis, H., and N. Sharon (1973) The biochemistry of plant lectins (phytohemagglutinins). Annu. Rev. Biochem. 42: 541-574.

Lowry, O. H., N. J. Rosebrough, A. L. Farr, and R. J. Randall (1951) Protein measurement with the Folin phenol reagent. J. Biol. Chem. 193: 265-275.

Marchesi, V. T. (1975) The structure and orientation of a membrane protein. In Cell Membranes: Biochemistry, Cell
Biology and Pathology, G. Weissmann and R. Claiborne, eds., pp. 45-53, HP Publishing Co., New York.

Margolis, R. U., and R. K. Margolis (1977) Minireview: Metabolism and function of glycoproteins and glycosaminoglycans in nervous tissue. Int. J. Biochem. 8: 85-91.

Meyer, D. I., and M. M. Burger (1976) The chromaffin granule surface: Localization of carbohydrate on the cytoplasmic surface of an intracellular organelle. Biochim. Biophys. Acta 443: 428-436.

Nett, T. M., A. M. Akbar, G. D. Niswender, M. T. Hedlund, and W. F. White (1973) A radioimmunoassay for gonadotropin-releasing hormone (Gn-RH) in serum. J. Clin. Endocrinol. Metab. 36: 880-885.

Palade, G. (1975) Intracellular aspects of the process of protein synthesis. Science 189: 347-358.

Pelletier, G., F. Labrie, R. Puviani, A. Arimura, and A. V. Schally (1974) Immunohistochemical localization of luteinizing hormone-releasing hormone in the rat median eminence. Endocrinology 95: 314-317.

Putney, J. W., Jr., C. M. VandeWalle, and B. A. Leslie (1978) Stimulus-secretion coupling in the rat lacrimal gland. Am. J. Physiol. 235: C188-C198.

Sharon, N., and H. Lis (1972) Lectins: Cell-agglutinating and sugar-specific proteins. Science 177: 949-959.

Shur, B. D., and S. Roth (1975) Cell surface glycosyltransferases. Biochim. Biophys. Acta 415: 473-512.

Singer, S. J. (1975) Architecture and topography of biologic membranes. In Cell Membranes: Biochemistry, Cell Biology and Pathology, G. Weissmann and R. Claiborne, eds., pp. 35-44, HP Publishing Co., New York.

Smith, E. E., and I. J. Goldstein (1967) Protein-carbohydrate interaction. V. Further inhibition studies directed toward defining the stereochemical requirements of the reactive sites of concanavalin A. Arch. Biochem. Biophys. 121: 88-95.

So, L. L., and I. J. Goldstein (1968) Protein-carbohydrate interaction. XIII. The interaction of concanavalin A with $\alpha$-mannans from a variety of microorganisms. J. Biol. Chem. 243: 2003-2007.

Styne, D. M., P. C. Goldsmith, S. R. Burnstein, S. L. Kaplan, and M. M. Grumbach (1977) Immunoreactive somatostatin and luteinizing hormone releasing hormone in median eminence synaptosomes of the rat: Detection by immunohistochemistry and quantification by radioimmunoassay. Endocrinology 101: 1099-1103.

Walsh, F. S., B. H. Barber, and M. J. Crumpton (1976) Preparation of inside-out vesicles of pig lymphocyte plasma membrane. Biochemistry 15: 3557-3562. 